nent, and temples flattened and hollowed into shallow concavities. The patient was dozing; lying on the right side, in which he had been recently placed, for his debility prevented any effort on his part. The respirations were very low and almost imperceptible, but regular. Pulse 120; small, wiry, and irritable; he opened his eyes without displaying any excitement; the countenance then appeared calm, but wan and ghastly; no expression of anxiety, (in the niedical sense); it was that of exhaustion rather than pain; skin of moderate temperature. Pulse of the same character as when he dozed. Tongue dry, red, and inclined to brown; surface not glazed, but rough, and papilla prominent; no sordes on tongue, teeth, or lips; the latter parched.

In a hollow, faint voice, he stated that he felt no pain, but very weak and exhausted. As his conclition required that he should be disturbed as little as possible, I only examined the abdomen, by passing my hand over it, and ascertaining that it was flat and hollow, and much shrunken, but no irregularity or unusual hardness or tenderness. His mother stated that there were no petechire on the surface, nor bedsores. The bowels had been occasionally irritable from yellowish fluid dejection; urine scanty, but clear.

It was stated to me that in the first week of the month of September, he had suffered from an accident on the Great Northern Railway; that he became confused in his head, and shortly after had an attark of fever, with delirium; the surface of the abdomen being covered with maculge, with a yellowish ochry diarrhœa; that in about three weeks he became convalescent, and was up and about, but that he had suffered a relapse; and for the last four weeks had been attended by the before-named representatives of the Hahnemannic practice. Mr. Russell informed me-and he obtained his information from the gentleman's partner-that the treatment had been minute quantities of syrup of cherries, and syrup of raspberries, and a tea-spoonful of chicken-broth, diluted with water, three or four times daily. This latter amount of nutriment was confirmed by the mother, who was told that any larger quantity would be detrimental.

I had nothing to do with the previous treatment, as it only reached me on hearsay, except the dietary. But the opinion I gave was, that the present condition of the patient was that of exhaustion from want of proper support, rather than as the sequel of fever; and unless a different plan of treatment were adopted the patient must die of inanition. The whole aspect of the patient justified this conclusion. His condition wanted the usual characteristics of the prostrate exhaustion of typhoid fever. The eye and intellect were too clear; there had not been for weeks any stupor-on the contrary, most wearisome and exhausting wakefulness. Of late some wandering, both during the scanty periods of sleep, or rathor dozing, and the long waking intervals. Neither the tongue, the pulse, nor the skin, exhibited the indication of fever. Whatever might have been his preceding condition in September, it was very obvious that his present state was the prostration of inanition.

This patient reminded me forcibly, only in an exaggerated form, of those cases of exhaustion, that those who have charge of our public hospitals must have repeatedly witnessed, of patients who have struggled through an attack of fever, neglected, and in want and wretchedness, but being found out by some good Samaritan, and being passed into an hospital, have rapidly improved, under simple nutrition and judiciously proportioned stimulants.

I urged the imperative necessity of immediately administering cautious quantities of the simpler forms of nourishment, with small quantities of port-wine freely diluted. I learn that he rapidly convalesced. Mr. Russell did not, however, continue to attend him, but I hear from him that the family feud was compromised by their declining the further attentions of the homcopathists, and confiding the patient to the attentive solicitude of his mother, who had been opposed to the homceopathic practice, and had consulted Mr. Russell. She, guided by the advice we had giren her, soon found that there was no death in nutrition, and that port-wine was not quite so poisonous as had been represented to her.

I think, Sir, this case forcibly illustrates the evils of this visionary system of practice. Solong as the homoepathist has to deal with mere dyspeptics or credulous and easily deluded hypochondriaes, his scheme may amuse the mind, but cannot harm the body; but.in the more -serious and acute forms of disease, it becomes a question of some moment how the public can protect themselves against the serious consequences of so much ignorance.

In this case the patient was carried to the very threshold of the grave-a sacrifice to a perverse adherence to a visionary hypothesis, in spite of the palpable, unmistakeable evidence of a starving man before them. Their daily answer was, "they were waiting for the crisis"! and the only crisis that their views would have recognised would have been the crisis of death.

Chester-street, Grosvenor-place, 1851.

\section{EPILEPSY AND QUININE.}

\section{BY W. G. MAXWELL, M.D., Garrison Surgeon, India.}

Tre severest fit of epilepsy can be arrested by a large dose of quinine. The periodicity also is destroyed by this medicine, and (by due attention) the disease cured.

CASE.-A tall, stout, well-made labourer (Ryot) was seized with a severe fit of epilepsy at five A.M. I saw him about seven, by accident. He was lying in a dark corner, with an old blanket thrown over him. I was informed he was subject to these fits; that he wonld continue in them for three days; that nothing was done, except occasionally (if the fits were severe) throwing some cold water over him. I immediately set about trying what I could do for him.

Ammonia, counter-stimulants, blisters, emetics, purgatives, cold, heat, \&c., were all tried without the slightest relief. The bowels were freely open involuntarily-freculent, semi-consistent, light colour. Free vomiting of phlegm, rice water, \&c. was also going on without the slightest relief. I now thought of trying quinine, as follows: Disulphate of quinine, twenty grains; aromatic tincture, one ounce; hot water, three ounces. This was gradually given with much difficalty, (as will easily be imagined, as hot as possible, in teaspoonfuls at a time. By the time half had been taken there was an evident remission in the severity of the symptoms; and by the time the whole of the draught had been got down the fits bad ceased to return. He fell off to sleep, and slept soundly for three hours; he was well covered up, and perspired most profusely, - one of the effects of the quinine.

Remarks. - It is almost needless for me to point to the importance of paying due attention to the power of sol-lunar influence at certain periods, in reference to this disease, as well as to the great exciting cause of irregularity (excess especially) in diet. And as we can control the disease (which necessarily includes its periodicity) at an early period, we shall prevent the almost certain tendency of repeated attacks to terminate in a fatal or incurable organic lesion.

India, South Division, 1851 .

\section{Sforeign}

\section{A Substitute for Mercury in Syphilitic Diseases.}

M. E. RoBIN has read a paper before the Academy of Sciences of Paris, with the following title, - "On Certain New Agents calculated as Substitutes for Mercury when used as an Anti-syphilitic Remedy." In former papers, M. Robin". had maintained these propositions: - "Mercurial preparations do not act in a peculiar manner when administered in syphilitic diseases; they merely combine with the virus and change it into a new or inert compound. Now there are a great many substances which form analogous combinations with organized matter, which substances probably have, like mercury, anti-syphilitic virtues; and it will be found that the agents of this class, which have thus been successfully employed, belong to the antiseptic division of remedies which act by combining with the noxious principles. In this manner we can understand whence arise the anti-syphilitic properties of arsenical, gold, silver, steel, and antimonial preparations. Hence arises the likelihood of success, if attempts be made to use such organic substances as the bichromate of potash, or sesquichloride of iron, instead of mercurials."

M. Robin induced Dr. Vicenti, of Paris, to try a few experiments with the bichromate of potash to combat syphilis; the salt was employed in three cases with much success, and of these one was marked by very severe secondary symptoms. Fifteen grains of the bichromate were divided into eighty pills, with extract of gentian. One of these was taken night and morning. They agreed pretty well with the stomach, though some opium was necessary to prevent nausea and vomiting. The patient took 240 pills in the space of about three months, and was then quite well of a very intense attack of iritis, accompanied by other syphilitic symptoms, which had almost blinded him. The patient had had an indurated chancre, and had never taken any mercury. 